\title{
A MEASURING WEIGHT MODEL OF TIMOR'S BEEF CATTLE BASED ON IMAGE
}

\author{
Deddy B. Lasfeto ${ }^{\# 1}$, Markus DaudLetik ${ }^{* 2}$ \\ ${ }^{\# 1}$ Electrical Engineering, State Polytechnic of Kupang, Kupang, Indonesia \\ ${ }^{* 2}$ Electrical Engineering, State Polytechnic of Kupang, Kupang, Indonesia \\ \#1 deddy_lasfeto@yahoo.co.id,*2md_letik@yahoo.com
}

\begin{abstract}
This study uses a digital camera to take pictures of Beef Cattle and do image processing to determine the physical size of the body of Beef cattle that looked. On the input image that captured by the camera will do the process of image segmentation to separate the image of beef cattle from the background and eliminates the other objects in the image that are nuisance. Furthermore, with computer vision made the process of identifying specific points of physical of Cattle that used to determine body weight (computational) of Beef Cattle automatically.

Determining the weight of Timor's Beef cattle based on image, is presented by the physical characteristics of cattle that is looked: the body length and width of the chest of cattle, and compute cattle weight based on conversion formula that standardized and generally recognized. This Image analysis system is able to actualize the value of body length and width of chest from the pixel values shown in the image.
\end{abstract}

The system has built two models namely Manual models and Maximum Expectations models. On manual models, the user can input a defining point of body length and width of chest in the image that appears on the computer system. In the maximum expectation, users no longer need to input these points but this image-based analysis system will do the computation automatically.

Keywords : Image Processing, Beef Cattle,Computer Vision, Manual Mode, Maximun expectation

\section{INTRODUCTION}

Sale and purchase of cattle between farmers and buyers are often found in Timor Island Indonesia, is still based on rough estimates in determining body weight. Generally agreed price through bargaining is not based on actual body weight. In addition, to the official animal markets, measurement facilities of the weigth of Beef Cattle are not always there. Sales of cattle that are not through weighing in advance may result in damages to the breeder or buyer.

Using mechanical weighing scales still have obstacles faced in conducting weighting cattle bodies, Lasfeto, et al $(2008)^{[1]}$, that are:

- Keep proper calibration of measuring instruments in order to know the actual weight of cattle;

- When cattle forced to climb the scales then stress conditions can also affect to cattle, besides cattle is not in a fixed position and always moving can affect the reading of the actual value in the designation of measuring instruments;

- Need to steer cattle to climb the scales are provided, it also requires a sizeable human assistance;

- Measure the weight of cattle which is done mechanically, which generally results in cattle experienced stress, can lose weight of cattle $( \pm 2 \%)$, in addition to other factors, such as the possibility of injuries due to friction barrier enclosure.

To get a more practical and more economical, Electrical and Information Technology can be applied to provide solutions to these problems, by using image processing to determine the physical size of the body of the Beef cattle that looks and its weight.

This study aims to find another way instead of mechanical scales to measure the weight of Beef cattle. Specific targets are expected to be achieved has information technology products more efficiently and economically effective (in terms of: time, cost, and manpower) used the society, especially farmers on Timor island to measure the weight of Beef Cattle.

\section{A. Literature Review}

\section{LITERATURE REVIEW AND HYPOTHESIS}

Some research in the field of animal husbandry, especially in breeding beef cattle, theorized that the determination of body weight of beef cattle can be done by measuring the chest circumference and body length of the animal. Between body length, chest circumference and body weight of cattle has a linear relationship $(\mathrm{McNitt}, 1983)^{[2]}$. According to Soenarjo $(1988)^{[3]}$, the chest circumference and body weight of cattle there is a 
positive correlation. This shows that if had known measures of livestock body can then be made an equation that describes the relationship between each the size of linear body with the weight of his body.

Ensminger and Olentine $(1980)^{[4]}$, revealed the method of determining the weight of beef cattle, as in Figure 1 below are:

1) measure the width of the chest, from points behind the scapula (c), down encircling the bottom of the body, behind the elbow (d);

2) measure the length of the body, which is the length from point of shoulder to the sitting bones (pin bone), namely from point a to point $b$.

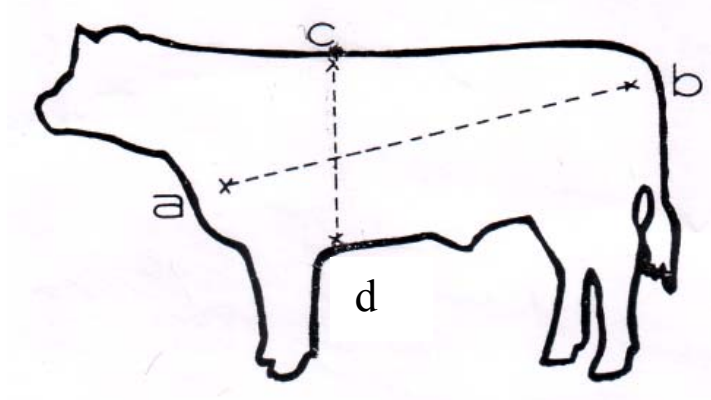

Figure 1. Determination of body length and width of chest cattle ${ }^{[4]}$

According Schoorl written by Siregar $(2007)^{[5]}$, the conversion of the physical size of the body that seemed to weigh cattle is (measurement formula is valid for adult beef cattle):

Body Weight $=\frac{(\text { Width of Chest }+22)^{2}}{100}$

Body Weight in $\mathrm{kg}$

Width of Chest (WoC) in $\mathrm{cm}$

According Soeprapto, et al $(2006)^{[6]}$, the body weight of cattle can be calculated by the formula:

$$
B W=\frac{B L+(C C)^{2}}{10840}
$$

BW (Body Weigt) in kg

BL (Body Lenght) in $\mathrm{cm}$

CC (Chest Circumference) in $\mathrm{cm}$ of the chest are:

According Murtidja (1993) ${ }^{[7]}$, determination of the weight of beef cattle by size body length and width

$B W=B L \times W C \times 70$, where:

$\mathrm{BW}(\mathrm{kg}), \mathrm{BL}(\mathrm{m}), \mathrm{WoC}(\mathrm{m})$

All results of this study indicate that the body length and width of chest can be used to calculate the weight of Beef cattle. It is a reference that in this study, gain weight length and width of the chest of the Beef Cattle is the main to be achieved in image processing.

Image representation relates to characterizing the quantity represented by each pixel. The image can declare the object luminance (e.g on pictures taken with the camera), the nature of absorption by the body tissues (X-ray imaging), the temperature profile (infrared imaging) and others. In general, the image is defined as a continuous function on the light intensity $\mathrm{f}(\mathrm{x}, \mathrm{y})$ in a two-dimensional field. The magnitude of $\mathrm{x}$ and $\mathrm{y}$ express coordinates, while the value of $\mathrm{f}$ at any point $(\mathrm{x}, \mathrm{y})$ expressed the intensity or brightness or degrees of gray at that point. A digital image is a continuous image is converted into a discrete form of both coordinates and intensity.Digital image can be regarded as a matrix with rows and columns indexes express the coordinates of each point in the image, and the value of each element expressed the light intensity at that point.One point on the digital image can be identified with a pixel.

Spatial characteristics of each object can be expressed by the level of gray, the joint probability distribution or spatial distribution. Feature objects simplest and perhaps most useful is the amplitude of its physical properties, such as reflectivity, transmissivity, tristimulus values (color), or responses multispekstral. For example, in the image of medical records with X-rays, the amplitude of gray levels representing the characteristics of absorption by the body tissue and can be used to distinguish between the bones with other networks or to distinguish between healthy tissue with healthy tissue (Jain, 1989) ${ }^{[8]}$. 
The expected goals of the segmentation process specifically on this study was to separate the background from the object (foreground). Therefore, to be a simple segmentation process, then the segmentation using edge detection. By using edge detection process, it will be obvious differences between the objects with his background.

Image segmentation is the first step in the process of image analysis that aims to take the information contained in the image. Image segmentation divides each image into parts or objects. To what extent such distribution is carried out depends on the problem at hand. Ideally, the segmentation step is stopped when the desired object has been successfully separated.

With an effective segmentation, likely will get a good result.Segmentation algorithms for monochrome image is usually based on one of two properties of gray-level values: discontinuity and similarity. At the discontinuity, the approach taken is to separate the image based on the change in value graylevel drastic. In contrast to the similarity, the approach is based on thresholding, region growing, region splitting and merging.

Image processing can be done with a computer when the image in digital form. Computer-assisted image analysis involves the study of feature extraction, segmentation and classification techniques. In computer vision systems, carried out pre-processing on the input image. The process of pre-processing may include image restoration, image enhancement or simply adjusting data representation only. The next process is the particular feature extraction for image segmentation into its components. The image is segmented into blocks input for the classifier.

According to Gonzalez and Woods (1993 ${ }^{[9]}$, To be able to recognize objects in an image, it would require some image analysis process first. In general, the image analysis process is divided into three parts, namely: the low level processing processing intermediate level and high level processing.

Computer vision is an automated process that integrates a large number of processes for visual perception, such as image acquisition, image processing, classification, recognition, and make a decision. Computer vision consists of techniques to estimate the characteristics of the object in the image, measurement characteristics associated with the geometry of the object, and interpret the geometry information, Lee, et all $(2001)^{[10]}$.

The processes in computer vision can be divided into three activities:

1. Obtain or acquire a digital image.

2. Perform a computational technique for processing or modify the image data (image processing operations).

3. Analyze and interpret the image and use the results of processing for a specific purpose, such as guiding robot, control equipment, monitoring manufacturing processes, and others.

B. Hypothesis

The results to be obtained through the image processing is to produce a body length, width of chest and weight of cattle based on standarized formula. The results were compared with the results of mechanical instrument, so the hypothesis in this study are: image processing analysis results do not differ significantly from the results of weighing using mechanical instrument.

\section{METHODODOLGY}

Research carried out, to determine the weight of beef cattle, based on the physical characteristics that are visible, and measurable. In this case the research object (objectimage) or a sample of Beef Cattle are: Timor's Beef Cattle and the number of beef cattle taken its image as much as 30 (thirty).

The overall structure of the image processing method to get the physical size of beef cattle that looks broadly demonstrated by the following diagram:

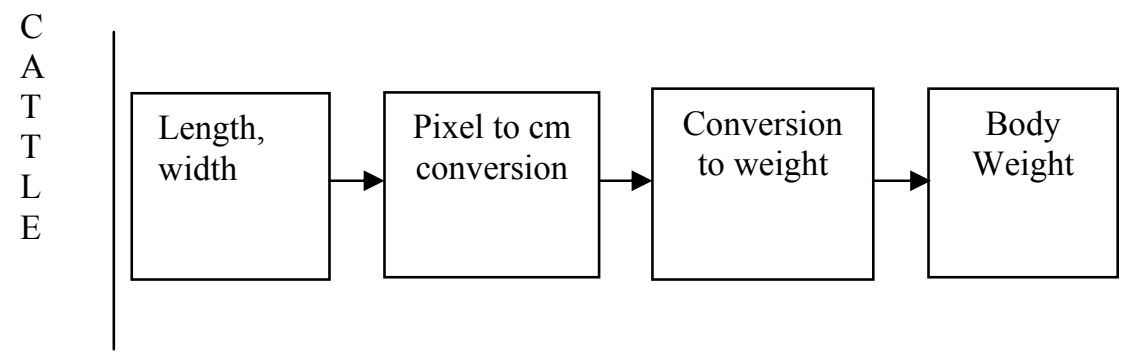

Figure2.Diagram of general process to Weighting the Cattle

The image of beef cattle will do image processing to get the size of the physical (body length and width of the chest) and then do the conversion process to get the cattle's body weight. 


\section{A. Image Acquisition}

Other factors that influence the success of the system built is the distance of image capture. In this study, the acquisition of objects within the image is different. However, in saving and performance testing system, one object image taken distances are varied but measured distance acquisition. This process, described in the following table:

Table 1.Distance image acquisition

\begin{tabular}{|c|c|c|c|c|}
\hline $\mathrm{n}_{(\mathrm{i})}$ & $\mathrm{d}_{(1)}$ & $\mathrm{d}_{(2)}$ & $\mathrm{d}_{(3)}$ & $\mathrm{d}_{(4)}$ \\
\hline \hline 1 & & & & \\
\hline \hline & \multicolumn{3}{|c|}{$\mathrm{d}$} \\
\hline 2 & \multicolumn{3}{|c|}{$\mathrm{x}$} \\
\hline$\ldots$ & \multicolumn{3}{|c|}{$\mathrm{x}$} \\
\hline 15 & \multicolumn{3}{|c}{$\mathrm{x}$} \\
\hline
\end{tabular}

note :

$\mathrm{n}_{(\mathrm{i})}=$ object image(beef cattle) $(\mathrm{i}=1,2,3, \ldots, 15)$

$\mathrm{d}_{(\mathrm{i})}=$ Distance acquisition $(\mathrm{i}=1,2,3,4)$ (meter)

$\mathrm{x}=$ distance acqusition/captured is not measured but definitely done randomly

Another factor is the shooting angle. In this study, the position of the photographer and image objects, arranged in a position approximately $\pm 90^{\circ}$ (perpendicular).In this image analysis, when use a different camera need to recalibration to get the number of pixels conversion to centimeters $(\mathrm{cm})$.

\section{B. Measurement}

At this stage, do measurement of the physical object as the body length, and the width of the chest of all the samples of cattle that become the object image. These measurements will be useful in the testing phase,as a comparison to measure the success of image processing systems are built.

\section{The Design of The System}

Perform image processing by using edge detection and image segmentation techniques to get physical features seen in cattle in accordance with the provisions in describing the physical weight of the cattle. Furthermore, we will convert the detection results of image processing into cattle weights.

In general, a system built through the groove in Figure 3.

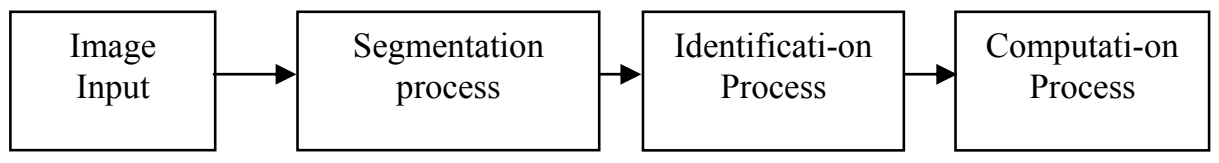

Figure3.Diagram of image processing procedures

On the input image from the camera will do the process of image segmentation to separate the beef cattle'simage from the background and eliminates the other objects in the image that are nuisance. Furthermore, with computer vision made the process of identifying specific points of physical of Cattle that used to determine body weight (computational) of Beef Cattle automatically.

\section{RESULT AND DISCUSSION}

This image analysis system is built using MATLAB programming language to implement image processing systems in computing the weight of the beef cattle. Input IAS (Image Analysis System) is a raster image of beef cattle and the output is weight in kilograms. image acquisition remains set at an angle perpendicular. The initial view of the IAS user interface found in Figure 4. 


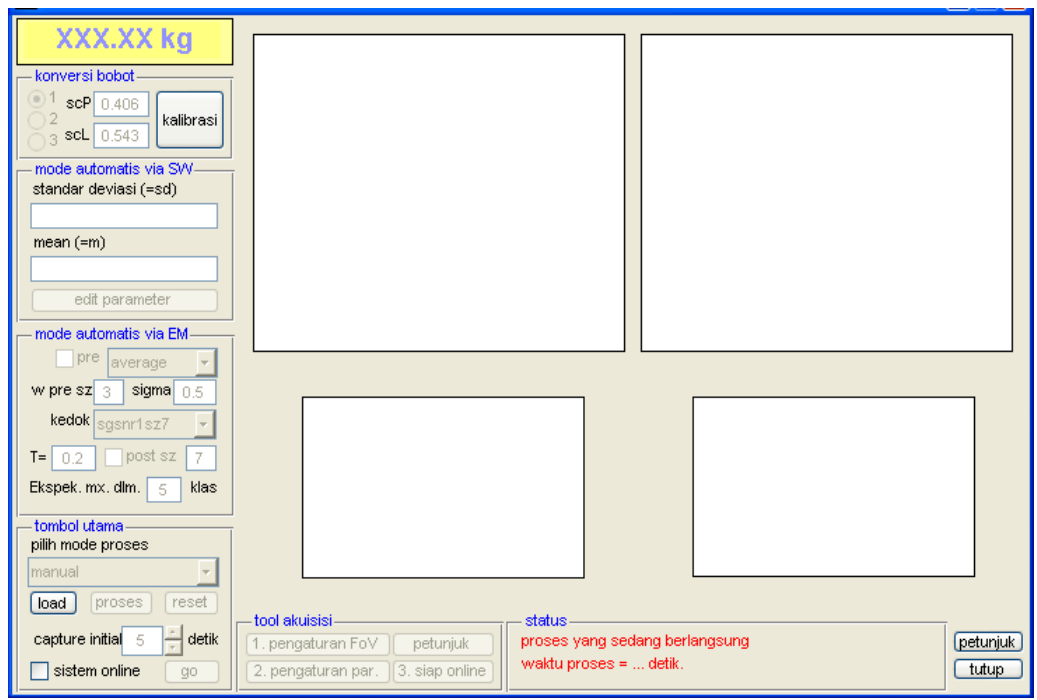

Figure4. The Interface of IAS

This system is by inputting its own image in this case it is necessary keystrokes load. Once the button is pressed, the load will be asked to input image to be processed.After the image is processed dinputkan IAS built into it, will continue in the mode of choice to use the manual and automatic mode selection to perform an analysis of the images of cattle being processed. Load button reading the image using imread function in image processing tool box.

Imread function syntax is:

varout=imread(filename).

Imread function to read the string file (the file name) and provide output matrix image on varout. Because image acquisition results have RGB format then varout the matrix dimensions $\mathrm{m} \times \mathrm{n} \times \mathrm{b}$ with respectively $m$ is the length of the image, $n$ is the width of the image, and color fields. In this research, the resolution of the images of cattle processed is $538 \times 403$ pixels.

\section{A. Calibration process}

Basic Mathematical Analysis :

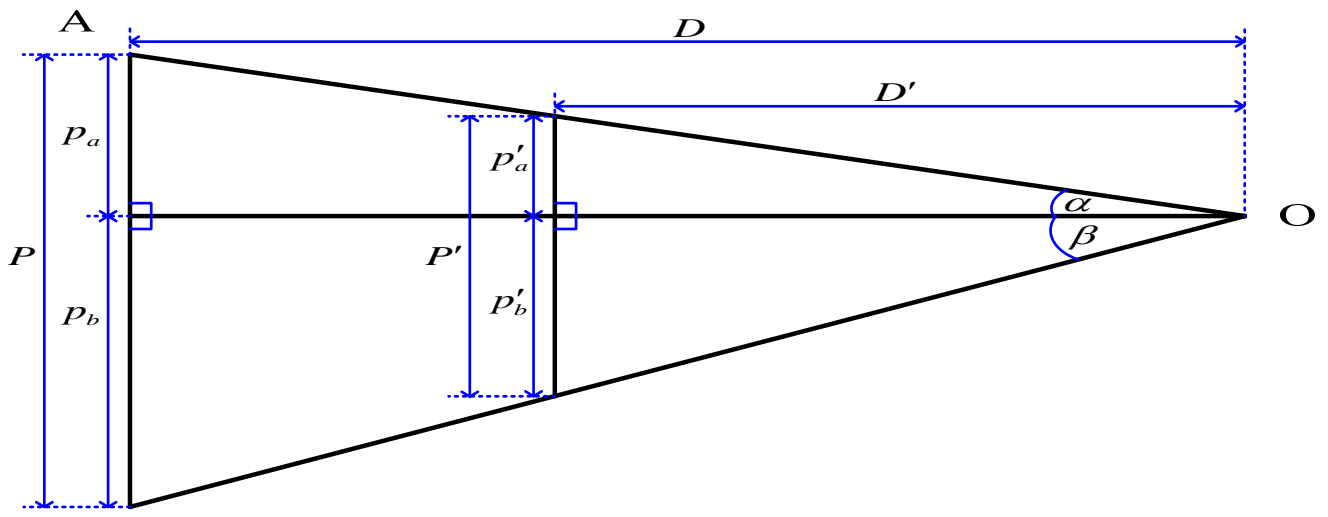

B

Figure 5. Tangensial mode

On Triangle OAB with:

$$
\begin{aligned}
& \tan \alpha=\frac{p_{a}}{D}=\frac{p_{a}^{\prime}}{D^{\prime}} ; \tan \beta=\frac{p_{b}}{D}=\frac{p_{b}^{\prime}}{D^{\prime}}, \\
& \frac{p_{a}+p_{b}}{D}=\frac{p_{a}^{\prime}+p_{b}^{\prime}}{D^{\prime}} . \\
& \frac{p_{a}}{D}+\frac{p_{b}}{D}=\frac{p_{a}^{\prime}}{D}+\frac{p_{b}^{\prime}}{D} \Rightarrow \tan \alpha+\tan \beta=\tan \alpha+\tan \beta .
\end{aligned}
$$


Thus obtained relation:

$$
\frac{p_{a}+p_{b}}{D}=\frac{p_{a}^{\prime}+p_{b}^{\prime}}{D^{\prime}} \Rightarrow \frac{P}{D}=\frac{P^{\prime}}{D^{\prime}} \Rightarrow P^{\prime}=\frac{P \times D^{\prime}}{D} .
$$

Magnitude P'is a lenght of projection of $\mathrm{P}$ on the distance D'.

By using the above evidence, the calibration process can be described in the following steps..

Ilustration the outdoor acqusition process of beef cattle image :

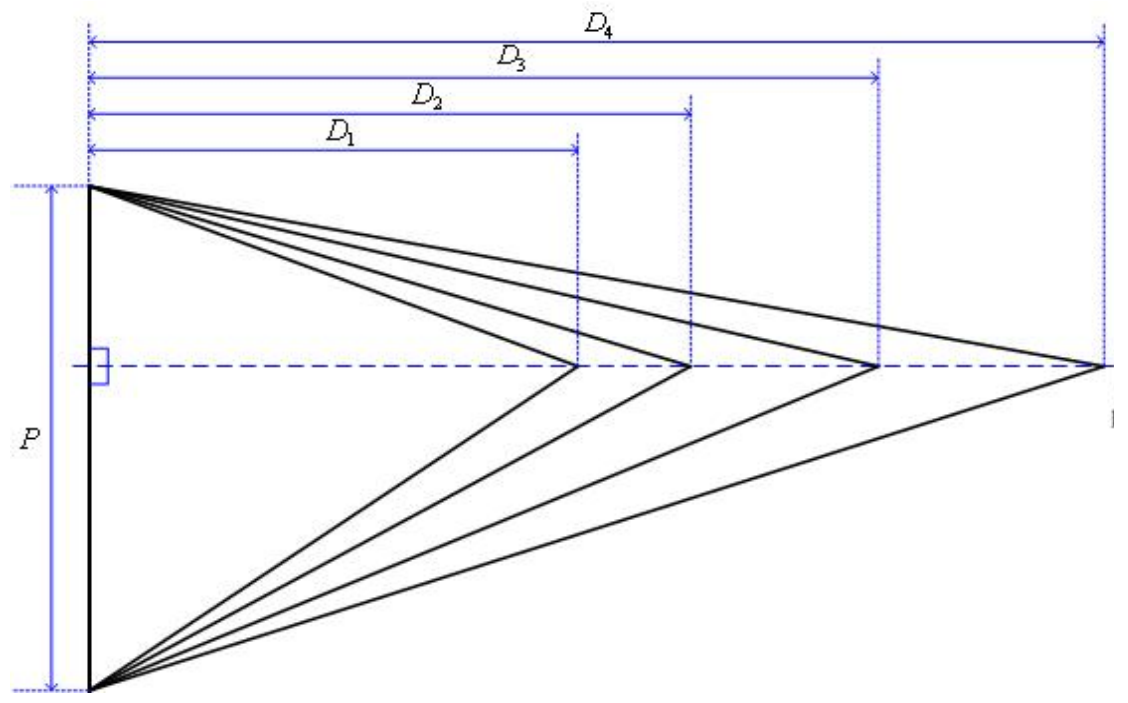

Figure 6.Ilustration the outdoor acqusition process of beef cattle image

The projection of $\mathrm{P}$ on the field taking the shortest distance D1, might look like the followingpicture:

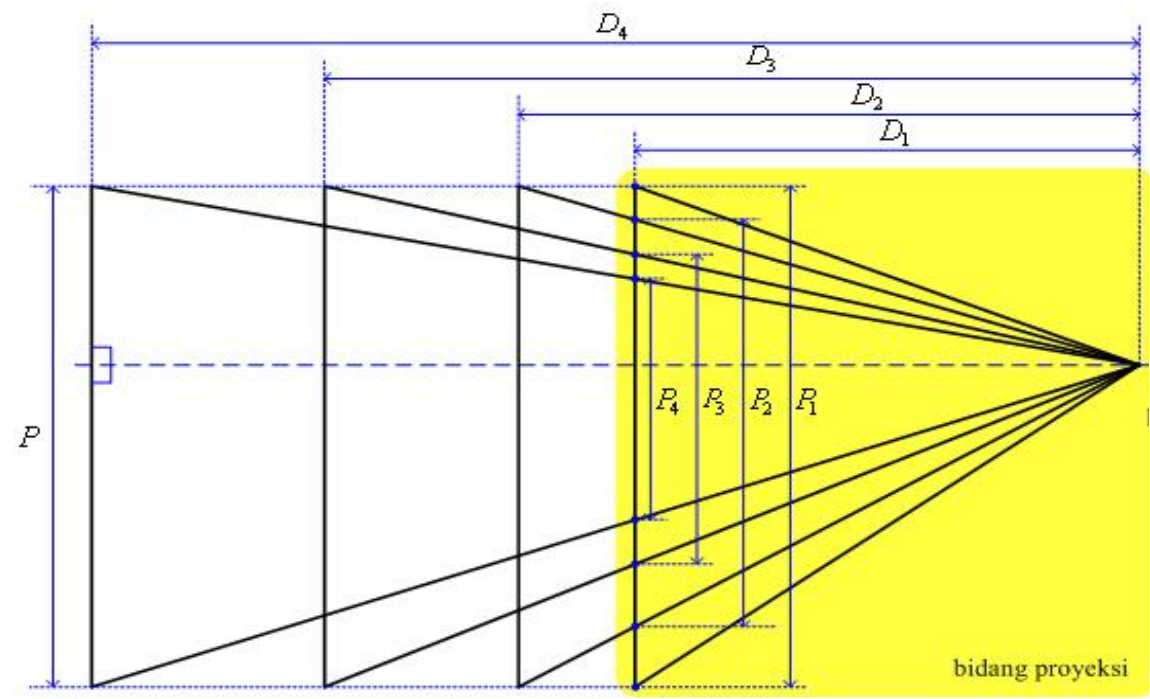

Figure 7.Projection on nearest distance captured

Use the tangens relation before, can obtained:

$$
\begin{aligned}
& P_{1}=\frac{P \times D_{1}}{D_{1}}=P, P_{2}=\frac{P \times D_{1}}{D_{2}}, \\
& P_{3}=\frac{P \times D_{1}}{D_{3}}, \text { and } P_{4}=\frac{P \times D_{1}}{D_{4}} .
\end{aligned}
$$

Ilustration image display on computer monitor: 


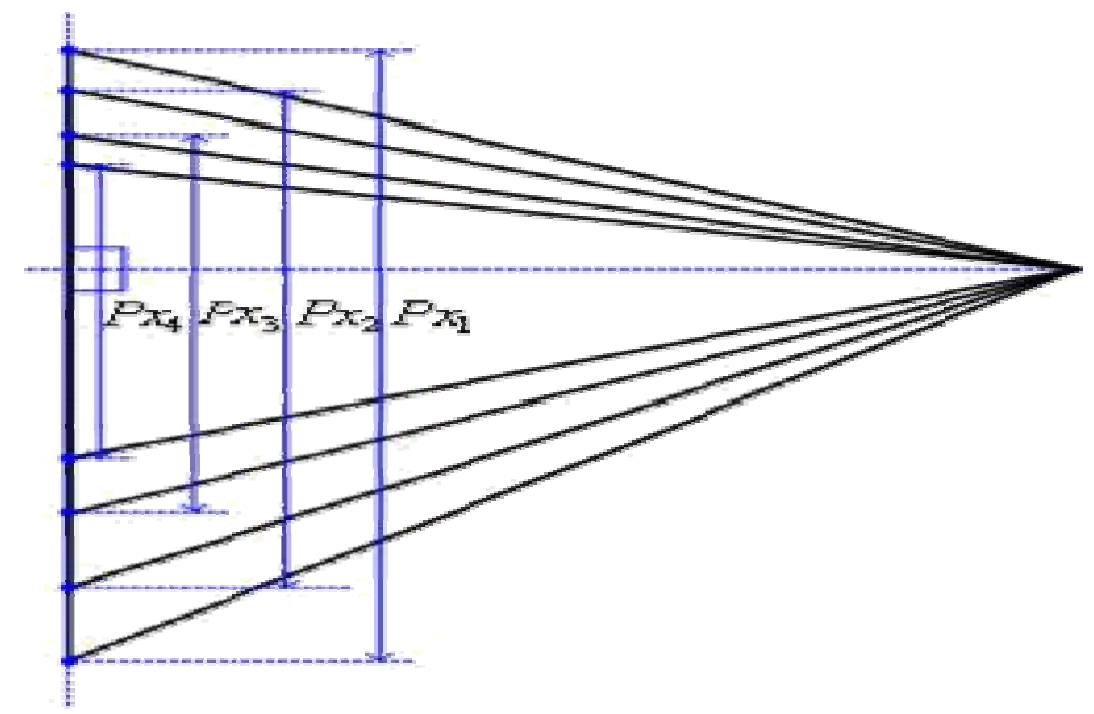

Figure 8. Ilustration image display on computer monitor

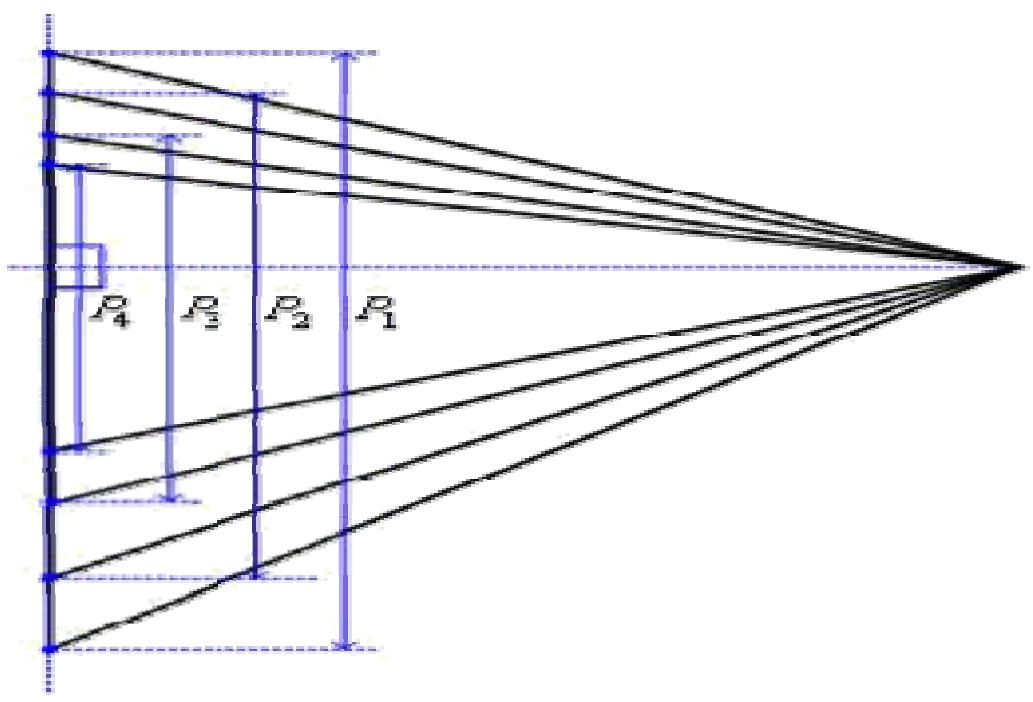

Figure 9.Illustration of the display of the image on the projection plane

We obtained that comoutation pixel scale to $\mathrm{cm}$ is:

$$
R=\frac{\sum_{i=1}^{n} \frac{P i}{P x i}}{n} \mathrm{~cm} / p x
$$

UsingR, and given the value of length ( $\mathrm{Lx})$ or Width $(\mathrm{Wx})$, in pixel unit, will obtained length and width ini cm unit ( $\mathrm{L}$ dan $\mathrm{W})$, as follow :

$$
\begin{aligned}
& \mathrm{L}=\mathrm{Lx} * \mathrm{R} \quad(\mathrm{cm}) \\
& \mathrm{W}=\mathrm{Wx} * \mathrm{R}(\mathrm{cm})
\end{aligned}
$$
model

we proposed the image processing is done in two models, namely: Manual model and Maximum Expectation

\section{B. Manual Model}

In this model, the system user needs to input the point of forming a body length and width of chest cattle on cattle The images displayed on the computer system. Model this stage is shown in the following algorithm:

1. Input the Image

2. Input 4 (four) points that define the point of forming a body length and width of chest of beef cattle 


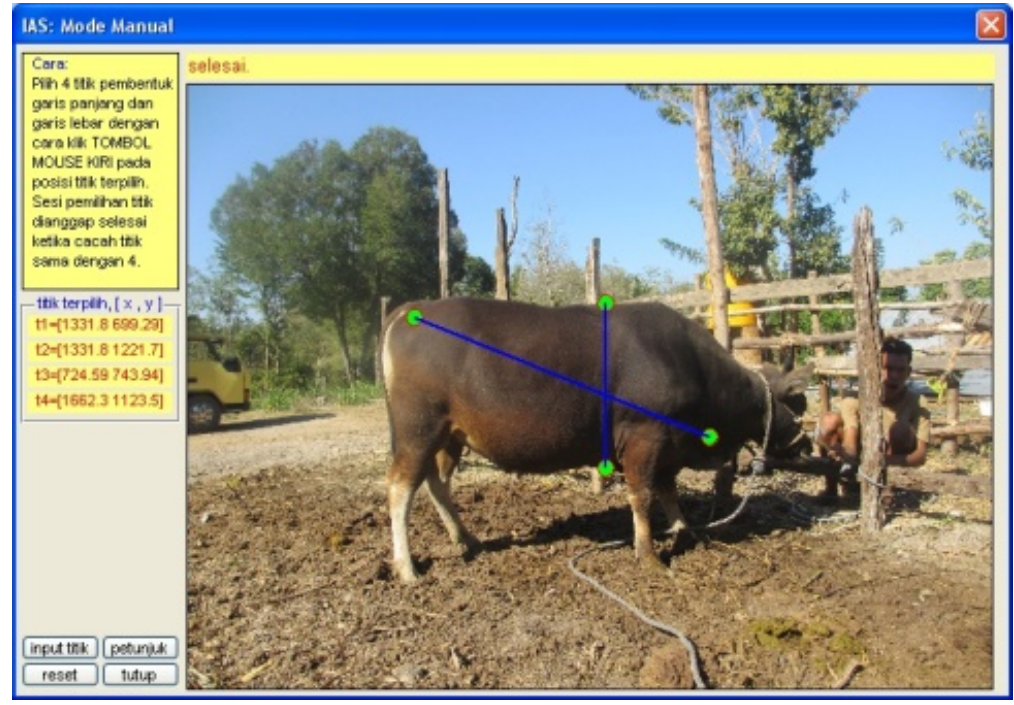

Figure 10. User Interface for manual model

3. Identification of two points to forming the line of body lenght and 2 points to forming the line of width of chest

4. Compute the distance of two lines of the body lenght and width of chest in pixel units

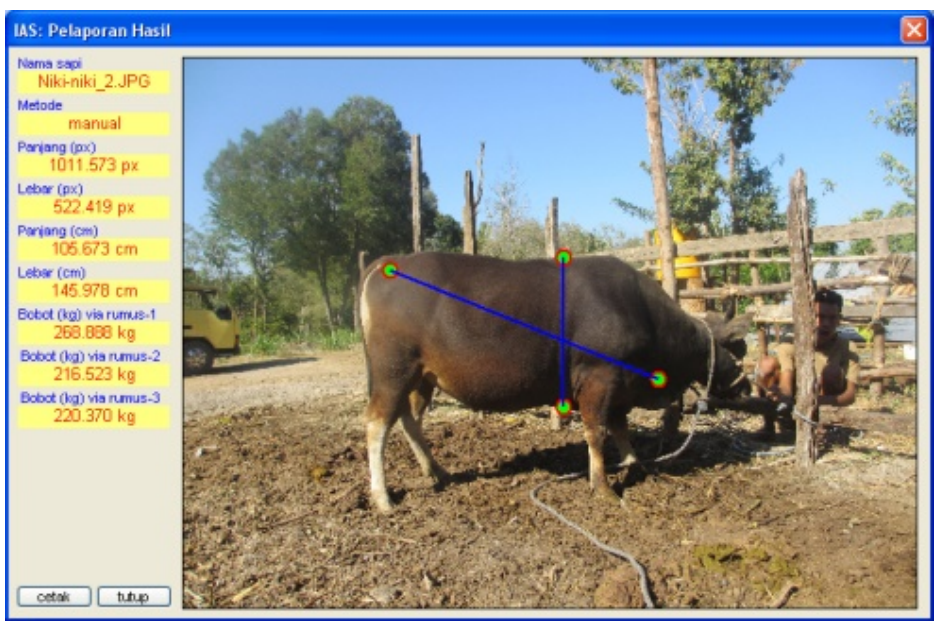

Figure 11. Compute distance in pixel units

5. Convesrion the pixel units to centimeters $(\mathrm{cm})$

6. Compute the weight of Beef Cattle

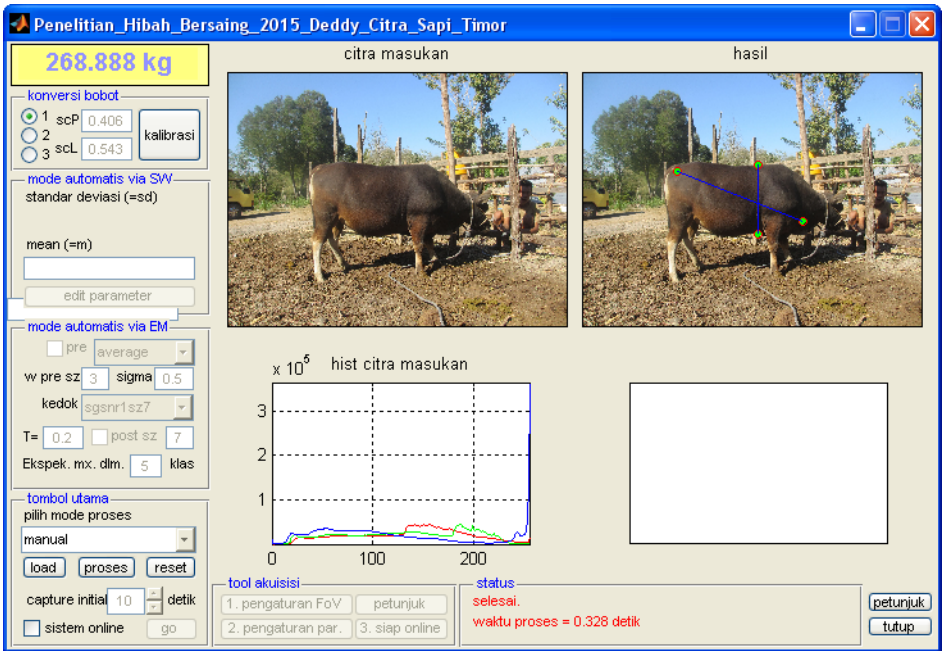

Figure 12. Result of computing in Manual Mode 
Weight conversion mode is shown in the diagram as follow:

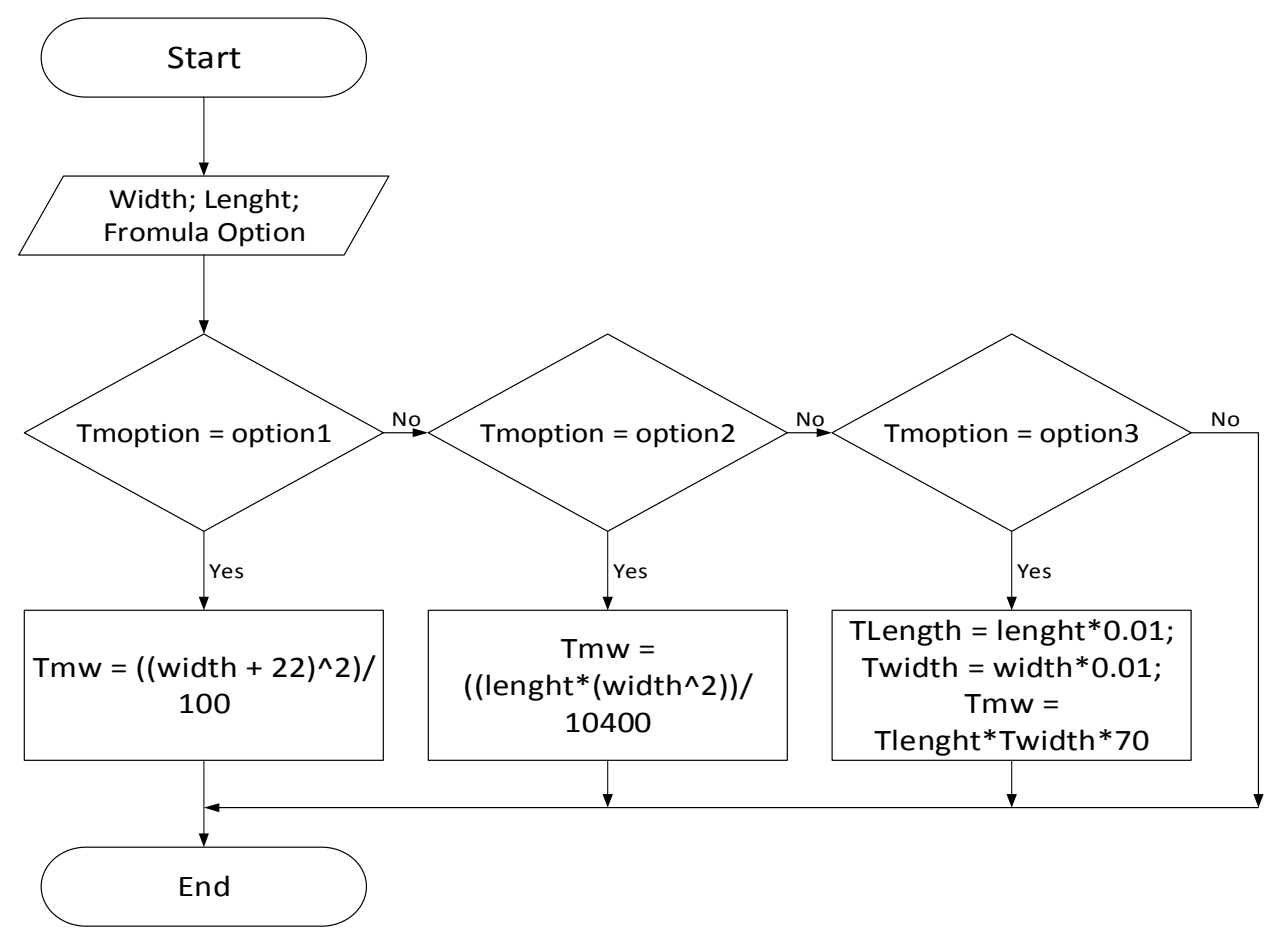

Figure 13.Computation Flowchart

Option of this computation program based on the formula that desribed before. When using the formula 2 or all 3 can be moved choice options that exist, and it will automatically display the value of the weight of beef cattle.

\section{Maximum Expectation Model}

In the maximum expectation model, without input the point of forming a body length and width of chest ofBeef cattle, but the system will automatically perform image analysis process after the beef cattle's image is inputted into the system. Image analysis models that have been implemented for the process automation of physical weighting of beef cattle using themaximum expectation method described in the following algorithm:

1. Input the image

2. Computeof edge map with color gradation technique

3. Projections the edge point in the horizontal and vertical direction

4. Compute the histogram of projection's point on horizontal and vertical directions

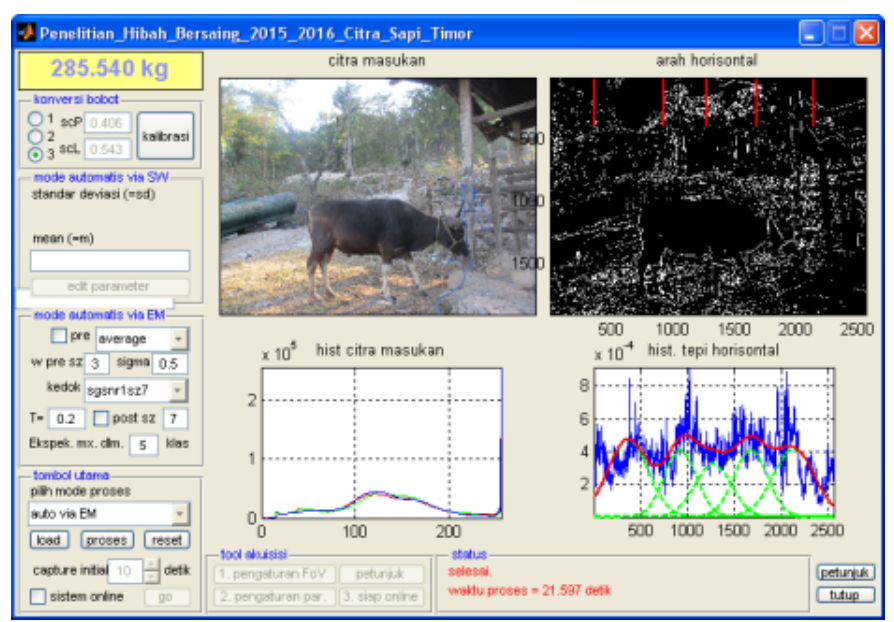

Figure 14.Computation of Histogram

5. Compute of Maximum Expectation (EM) on the histogram in horizontal and vertical directions based on a count of the class that entered 


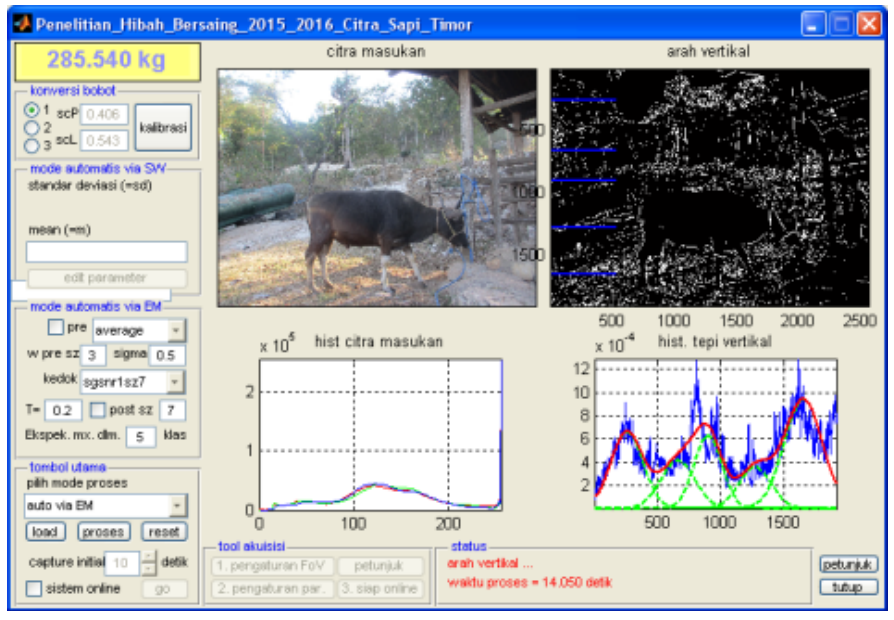

Figure 14.Computation of EM

6. Set four points of the EM curve as the point of forming a line of body length and width of chest of Beef cattle

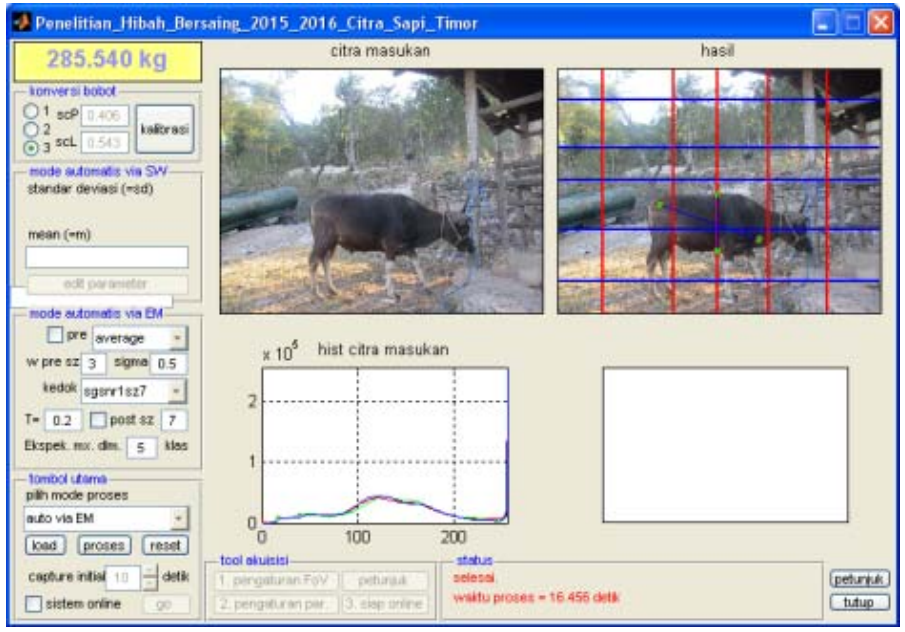

Figure 14.Four points setting

7. Identify two points that forming the line of body length and two poits that forming the line of width of chest

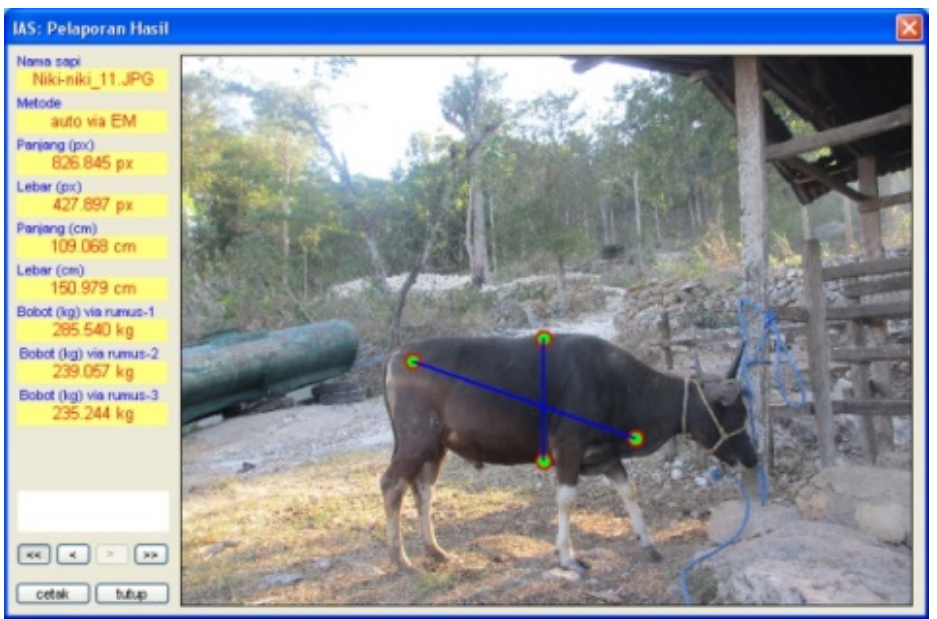

Figure 15.Indentification points of body lenght and width of chest

8. Compute the distance of the line of body lenghtand line of chest of body in pixel units.

9. Conversion the pixel units to centimeters unit.

10. Compute the weight of Beef cattle's body 


\section{Analysis of Indentification process}

To Determine the line of body length dan width of chest, these algoritm as follow:

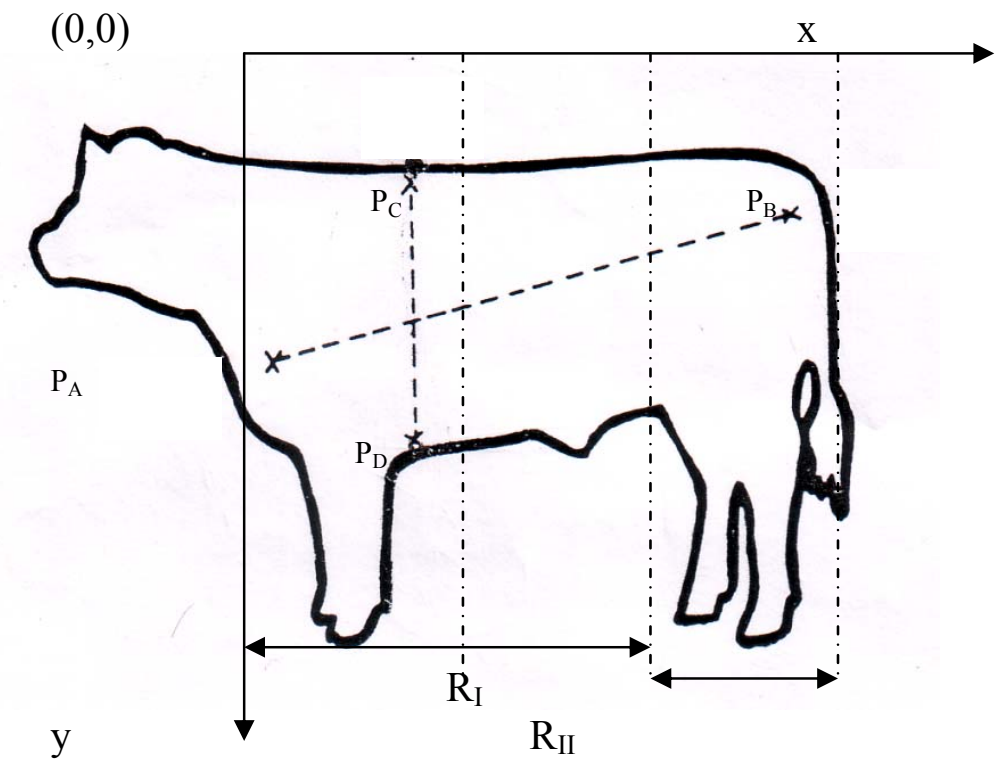

Figure 16. Identification process

1. Compute point of body length:

$\mathrm{P}_{\mathrm{A}}\left(\mathrm{x}_{1}, \mathrm{y}_{1}\right)$ to $\mathrm{P}_{\mathrm{B}}\left(\mathrm{x}_{2}, \mathrm{y}_{2}\right)$, fact $\mathrm{P}_{\mathrm{A}}\left(\mathrm{x}_{1},:\right)<\mathrm{P}_{\mathrm{B}}\left(\mathrm{x}_{2}\right.$, :)

2. Compute point of chest of body:

$\mathrm{P}_{\mathrm{C}}\left(\mathrm{x}_{3}, \mathrm{y}_{3}\right)$ to $\mathrm{P}_{\mathrm{D}}\left(\mathrm{x}_{4}, \mathrm{y}_{4}\right)$, in fact: $\mathrm{P}_{\mathrm{C}}\left(:, \mathrm{y}_{3}\right)<\mathrm{P}_{\mathrm{D}}\left(:, \mathrm{y}_{4}\right)$.

But probability $\mathrm{P}_{\mathrm{C}}\left(:, \mathrm{y}_{3}\right)<\mathrm{P}_{\mathrm{B}}\left(:, \mathrm{y}_{2}\right)$. A solution is: from $\mathrm{A}$ to $\mathrm{B}$ devided in 3 same parts in $\mathrm{x}$. That are two facts:

- Points A, C, and D are the same 2/3 area.

- $\quad$ unlikely $\mathrm{P}_{\mathrm{A}}\left(:, \mathrm{y}_{1}\right)<\mathrm{P}_{\mathrm{C}}\left(:, \mathrm{y}_{3}\right)$ and $\mathrm{P}_{\mathrm{A}}\left(:, \mathrm{y}_{1}\right)>\mathrm{P}_{\mathrm{D}}\left(:, \mathrm{y}_{4}\right)$.

3. Based on two facts above, it can determine the point of body length and width of chest are:

$\{\min (\mathrm{y})\} \in \mathrm{R}_{\mathrm{I}}$ to $\{\max (\mathrm{y})\} \in \mathrm{R}_{\mathrm{I}}$

become $\mathrm{P}_{\mathrm{C}}\left(\mathrm{x}_{3}, \mathrm{y}_{3}\right)$ to $\mathrm{P}_{\mathrm{D}}\left(\mathrm{x}_{4}, \mathrm{y}_{4}\right)$.

4. Point of determine width of chest are $\mathrm{P}_{\mathrm{C}}\left(:, \mathrm{y}_{3}\right)$ and $\mathrm{P}_{\mathrm{D}}\left(: \mathrm{y}_{4}\right), \mathrm{P}_{\mathrm{C}}(\mathrm{x}, \mathrm{y}):\left[\left(\mathrm{x}_{31}, \mathrm{y}_{31}\right),\left(\mathrm{x}_{32}, \mathrm{y}_{32}\right),\left(\mathrm{x}_{33}, \mathrm{y}_{33}\right), \ldots\right]$, and $\mathrm{P}_{\mathrm{D}}(\mathrm{x}, \mathrm{y}):\left[\left(\mathrm{x}_{41}, \mathrm{y}_{41}\right),\left(\mathrm{x}_{42}, \mathrm{y}_{42}\right), \quad\left(\mathrm{x}_{43}, \mathrm{y}_{43}\right), \ldots\right]$.

5. Compute the orientation of Beef Cattle:

Indexy $_{\text {maks }}=\max (\mathrm{P}(\mathrm{x},:))$

Distance to left $=\operatorname{abs}\left(\mathrm{P}(1,:)-\mathrm{P}\left(\right.\right.$ indexy $\left.\left._{\text {maks }},:\right)\right)$

Distance to right $=\operatorname{abs}\left(\mathrm{P}(\right.$ lenght $(\mathrm{P}),:)-\mathrm{P}\left(\right.$ indexy $\left._{\text {maks }},:\right)$

Beef Cattle is orient to left if: distance to left $<$ distance to right. Otherwise, Beef Cattle is orient to right if: distance to left $>$ distance to right.

6. Compute index the point to determine line of Width of chest:

If Beef Cattle orients to left, compute:

$\mathrm{T}=\mathrm{P}(1,:)+2 / 3(\operatorname{abs}(\mathrm{P}($ lenght $(\mathrm{P})-\mathrm{P}(1,:)))$

$\mathrm{xcut}=\operatorname{logical}($ all index of $\mathrm{x}$ that smaller from $\mathrm{T})$

countindekx $x=\operatorname{sum}(x c u t)$

early inde $x=(P(x,:)=\min (P(x, 1$ :count index $x)))$

end index $=(\mathrm{P}(\mathrm{x},:)=\max (\mathrm{P}(\mathrm{x}, 1$ :count index $\mathrm{x})))$

If Beef Cattle orients to right:

$\mathrm{T}=\mathrm{P}(1,:)+1 / 3(\operatorname{abs}(\mathrm{P}($ lenght $(\mathrm{P})-\mathrm{P}(1,:)))$ 
$\mathrm{xcut}=\operatorname{logical}($ all index $\mathrm{x}$ that greater than $\mathrm{T})$

count index $x=\operatorname{sum}(x c u t)$

early index $=(\mathrm{P}(\mathrm{x},:)=\min [\mathrm{P}(\mathrm{x}$, length $(\mathrm{P})-$ count index $\mathrm{x}$ : length $(\mathrm{P})))]$

end index $=(\mathrm{P}(\mathrm{x},:)=\max [(\mathrm{P}(\mathrm{x}$, length $(\mathrm{P})-$ count index $\mathrm{x}$ : length $(\mathrm{P})))]$

The points to determine line of chest of body are $\mathrm{P}$ (early index) and $\mathrm{P}$ (end index).

7. Compute the distance of point A to B and C to D use Euclidean (Ahmad, 2005) ${ }^{[11]}$ :

$$
\begin{gathered}
d\left(\left[x_{1}, y_{1}\right],\left[x_{2}, y_{2}\right]\right)=\sqrt{\left(x_{1}-x_{2}\right)^{2}+\left(y_{1}-y_{2}\right)^{2}} \\
\text { V. CONCLUSION }
\end{gathered}
$$

Based on the findings and analysis conducted can be concluded as follows:

1. The process of camera calibration and image system to get the actual value of beef cattle's specifically body length and width of chest of beef cattle is very fundamental to the success of the analysis of this image, because the pixel values of the beef cattle's image that captured greatly affects the actual value of the body length and width of chest of the beef cattle.

2. The use informatics techniques of image-based to determine the weight of Timor's beef cattle, can be done in two modes namely, the manual mode by means of inputting the defining point of body length and width of chest of beef cattle on cattle image that displayed on the computer monitor, and can also be done automatically without inputting the point. This automatic system that we proposed namely the maximum expectation mode.

3. Determine the weight of Timor's beef cattle done with image-based method using conversion formula that standardized and generally recognized

\section{ACKNOWLEDGMENT}

This study was supported by Ministry of Research, Technology, and Higher Education of Republic of Indonesia in 2016

\section{REFERENCES}

[1] Lasfeto,D.B, Susanto, A, Agus,A. 2008. The Application of Image Processing to Estimate the Live Weight of Beef Cattle, Gadjah Mada University Indonesia

[2] McNitt, J, I. 1974. Livestock Husbandry Techniques. Suffolk : The Chaucer Press

[3] Soenarjo, Ch. 1988. A View Animal Science Lecture. Jakarta : CV. Baru

[4] Ensminger,E,M ; \& G.C.Olentine, Jr. 2000. Feeds \& Nutrition - Complete. West Sierra Avenue Clovis California : The Ensminger Publishing Company

[5] Siregar,S. B.,2007. Fattening Cattle. Jakarta : Penebar Swadaya.

[6] Soeprapto,H., Z.Abidin. 2006. How Fattening Beef Cattle. Jakarta : Agromedia Press

[7] Murtidja, B,A. 1993. Breeding Cattle. Yogyakarta : Kanisius

[8] Jain, K, Anil. 1989. Fundamental of Digital Image Processing. Prentice Hall

[9] Gonzalez, R. C., R.E.Woods, 1993. Digital Image ProcessingAddison-Wesley Publishing Company, Inc.

[10] Lee, B.,YanJia-yong., ZHUANG,Tian-ge.,2001, A Dynamic Programming Based Algorithm for Optimal Edge Detection in Medical Images, IEEE Proceeding of The International Workshop on Medical Imaging and Augmented Reality (MIAR'01).

[11] Ahmad, Usman. 2005. Digital Image Processing. Yogyakarta : Graha Ilmu Press

\section{AUTHOR PROFILE}

Deddy Barnabas Lasfeto (e-mail: deddy_lasfeto@yahoo.co.id), is a lecturer in Electrical Engineering, State Polytechnic of Kupang, Indonesia.

Markus Daud Letik (e-mail:md_letik@yahoo.com), is Head of Mechanical and Electrical Laboratory, State Polytechnic of Kupang, Indonesia. 